\title{
Development of $\mathrm{Li}_{2} \mathrm{TiS}_{3}-\mathrm{Li}_{3} \mathrm{NbS}_{4}$ by a mechanochemical process
}

\author{
Atsushi SAKUDA ${ }^{\dagger, \dagger \dagger}$, Tomonari TAKEUCHI ${ }^{\dagger \dagger}$, Masahiro SHIKANO, Koji OHARA ${ }^{* * *}$, \\ Katsutoshi FUKUDA*, Yoshiharu UCHIMOTO***, Zempachi OGUMI*, \\ Hironori KOBAYASHI and Hikari SAKAEBE \\ Research Institute of Electrochemical Energy, Department of Energy and Environment, National Institute \\ of Advanced Industrial Science and Technology (AIST), 1-8-31 Midorigaoka, Ikeda, Osaka 563-8577, Japan \\ *Office of Society-Academia Collaboration for Innovation, Kyoto University, Gokasho, Uji, Kyoto 611-0011, Japan \\ ${ }^{* *}$ The Research \& Utilization Division, Japan Synchrotron Radiation Research Institute (JASRI), \\ 1-1-1 Kouto, Sayo, Hyogo 679-5198, Japan \\ *** Graduate School of Human and Environmental Studies, Kyoto University, \\ Nihonmatsu-cho, Yoshida, Sakyo-ku, Kyoto 606-8317, Japan
}

Solid solution of $\mathrm{Li}_{2} \mathrm{TiS}_{3}\left(\mathrm{Li}_{8 / 3} \mathrm{Ti}_{4 / 3} \mathrm{~S}_{4}\right)$ and $\mathrm{Li}_{3} \mathrm{NbS}_{4}$ were prepared using mechanochemical syntheses. The materials with cubic rock-salt structure were obtained over the full range of compositions $\left(\operatorname{Li}_{(8+x) / 3} \operatorname{Ti}_{(4-4 x) / 3} \mathrm{Nb}_{x} \mathrm{~S}_{4} ; 0 \leqq x \leqq 1\right)$. Lithium, titanium, and niobium randomly share the cationic site. Each material showed electrode activity and had a large reversible capacity of more than $350 \mathrm{mAh} \mathrm{g}^{-1}$ with more than 3 electron process per composition formulas of $\mathrm{Li}_{(8+x) / 3} \mathrm{Ti}_{(4-4 x) / 3} \mathrm{Nb}_{x} \mathrm{~S}_{4}$.

(2017 The Ceramic Society of Japan. All rights reserved.

Key-words : Sulfide, Battery, Electrode, Mechanochemical synthesis

[Received November 14, 2016; Accepted January 7, 2017]

\section{Introduction}

There is great demand for the development of innovative, rechargeable batteries with high energy densities. We have developed a lithium/metal polysulfide battery as a potential candidate for this application. We (AIST) and Osaka Prefecture University have proposed that transition metal sulfide materials with high sulfur compositions, such as amorphous polysulfides of titanium, niobium, and molybdenum, ${ }^{1)-5)}$ and rock-salt lithium transition metal sulfides such as $\mathrm{Li}_{2} \mathrm{TiS}_{3}$ and $\mathrm{Li}_{3} \mathrm{NbS}_{4}$ with space group Fm$3 \mathrm{~m}^{6)-8)}$ can act as electrode active materials with large capacities. These compounds exhibit high reversible capacities of ca. 400 $\mathrm{mAh}^{-1}$, which are two to three times larger than those of practical positive electrode materials, although the potential thereof is almost halved (ca. $2 \mathrm{~V}$ ). Additionally, they also have high potential for long cycling performances. ${ }^{6)-8)}$ As an example, we reported that $\mathrm{Li}_{3} \mathrm{NbS}_{4}$ could be charged and discharged without drastic capacity fading for more than 200 cycles in the all-solid-state cells. ${ }^{8)}$

There are few reports on quaternary mixed sulfides with rocksalt structure and high lithium ratios. Many more of these new materials should have become available on the market, but this is not the case. This is predominantly due to the complex synthesis of lithium-containing transition metal sulfides, because of their high reactivity with moisture and the high vapor pressure of sulfur. We have reported the straightforward synthesis of lithium-

Corresponding author: A. Sakuda; E-mail: a.sakuda@aist.go.jp i† Corresponding author: T. Takeuchi; E-mail: takeuchi. tomonari@aist.go.jp

tit Present address: Department of Applied Chemistry, Graduate of Enginnering, Osaka Prefecture University, 1-1 Gakuencho, Sakai, Osaka, 599-8531, Japan

tit广 Preface for this article: Dol http://doi.org/10.2109/jcersj2.125.P4-1 containing transition metal sulfides, readily prepared by a mechanochemical process using ball milling. ${ }^{6), 7)}$ The cubic rock-salt $\mathrm{Li}_{2} \mathrm{TiS}_{3}$ and $\mathrm{Li}_{3} \mathrm{NbS}_{4}$ prepared using this process show similar lattice parameters of ca. 5.06 and $5.13 \AA$, respectively. It is therefore expected that a solid solution be obtainable between them for a wide range of compositions.

In this paper, we report the solid solution of cubic rock-salt $\mathrm{Li}_{2} \mathrm{TiS}_{3}\left(\mathrm{Li}_{8 / 3} \mathrm{Ti}_{4 / 3} \mathrm{~S}_{4}\right)$ and $\mathrm{Li}_{3} \mathrm{NbS}_{4}$, prepared by mechanochemical synthesis. In the cubic rock-salts of $\mathrm{Li}_{2} \mathrm{TiS}_{3}$ and $\mathrm{Li}_{3} \mathrm{NbS}_{3}$, $\mathrm{Li} / \mathrm{Ti}$ and $\mathrm{Li} / \mathrm{Nb}$ randomly share the cationic site. An interesting aspect of the preparation of solid solutions between rock-salt type $\mathrm{Li}_{2} \mathrm{TiS}_{3}$ and $\mathrm{Li}_{3} \mathrm{NbS}_{4}$, is investigating whether the cubic rock-salt structure in which lithium (Li), titanium (Ti), and niobium $(\mathrm{Nb})$ share the cationic site is obtainable for a full range of compositions. Material costs and investigating whether properties such as capacity and conductivity are tunable in the formation of solid solutions are also important.

\section{Experimental}

Lithium titanium niobium sulfides with the composition $\mathrm{Li}_{(8+x) / 3} \mathrm{Ti}_{(4-4 x) / 3} \mathrm{Nb}_{x} \mathrm{~S}_{4}$ (where $x=0,0.31,0.57,0.80$, and 1) were prepared from lithium sulfide $\left(\mathrm{Li}_{2} \mathrm{~S}, 99.9 \%\right.$, Mitsuwa Pure Chemicals), titanium sulfide (IV) $\left(\mathrm{TiS}_{2}, 99.9 \%\right.$, High Purity Chemicals), niobium sulfide (IV) $\left(\mathrm{NbS}_{2}, 99 \%\right.$, High Purity Chemicals), and sulfur $\left(\mathrm{S}_{8}\right)$ as starting materials. The compositions are listed in Table 1. The chemical composition shown in the Table 1 is nominal composition estimated from the chemical composition of the starting materials.

The samples were directly synthesized by mechanochemical synthesis at room temperature using a planetary ball mill apparatus (P-7, Fritsch $\mathrm{GmbH})$. Stoichiometric amounts of starting materials were weighed and mixed, and the mixture was placed into a zirconia pot $(45 \mathrm{~mL})$ along with 500 zirconia balls $(4 \mathrm{~mm}$ in diameter). The pot was then placed in an argon-filled glove box. 
Table 1. Compositions of $x$ and $y$ in the composition formulas $\mathrm{Li}_{(8+x) / 3} \mathrm{Ti}_{(4-4 x) / 3} \mathrm{Nb}_{x} \mathrm{~S}_{4}$ and $\mathrm{Li}_{2+y} \mathrm{Ti}_{1-y} \mathrm{Nb}_{y} \mathrm{~S}_{3+y}$, atomic ratios, electronic conductivity of the powder compressed pellets $(\sigma)$, powder true density $\left(d_{\text {pow }}\right)$, density calculated by lattice parameters obtained by XRD measurements $\left(d_{\mathrm{XRD}}\right)$, reversible capacity (Cap.), and the composition range of $z$ in the composition formula $\mathrm{Li}_{z} \mathrm{Ti}_{(4-4 x) / 3} \mathrm{Nb}_{x} \mathrm{~S}_{4}$ during charging and discharging

\begin{tabular}{|c|c|c|c|c|c|c|c|c|c|c|}
\hline$x$ & $y$ & $\mathrm{Li}$ & $\mathrm{Ti}$ & $\mathrm{Nb}$ & S & $\begin{array}{c}\sigma \\
/ \mathrm{S} \mathrm{cm}^{-1} \\
\end{array}$ & $\begin{array}{c}d_{\text {pow }} \\
/ \mathrm{g} \mathrm{cm}^{-3}\end{array}$ & $\begin{array}{c}d_{\mathrm{XRD}} \\
/ \mathrm{g} \mathrm{cm}^{-3}\end{array}$ & $\begin{array}{c}\text { Cap. } \\
/ \mathrm{mAh}^{-1}\end{array}$ & $z$ range \\
\hline 0 & 0 & 2.667 & 1.333 & 0 & 4 & $1.1 \times 10^{-5}$ & 2.60 & 2.706 & 386 & $0.5-3.5$ \\
\hline 0.31 & 0.25 & 2.769 & 0.923 & 0.308 & 4 & $1.0 \times 10^{-5}$ & 2.74 & 2.777 & 377 & $0.5-3.6$ \\
\hline 0.57 & 0.5 & 2.857 & 0.571 & 0.571 & 4 & $1.2 \times 10^{-5}$ & 2.78 & 2.848 & 365 & $0.4-3.5$ \\
\hline 0.80 & 0.75 & 2.933 & 0.267 & 0.800 & 4 & $2.3 \times 10^{-5}$ & 2.90 & 2.922 & 356 & $0.4-3.5$ \\
\hline 1 & 1 & 3.000 & 0 & 1.000 & 4 & $1.0 \times 10^{-2}$ & 2.92 & 2.968 & 361 & $0.6-3.9$ \\
\hline
\end{tabular}

(a)

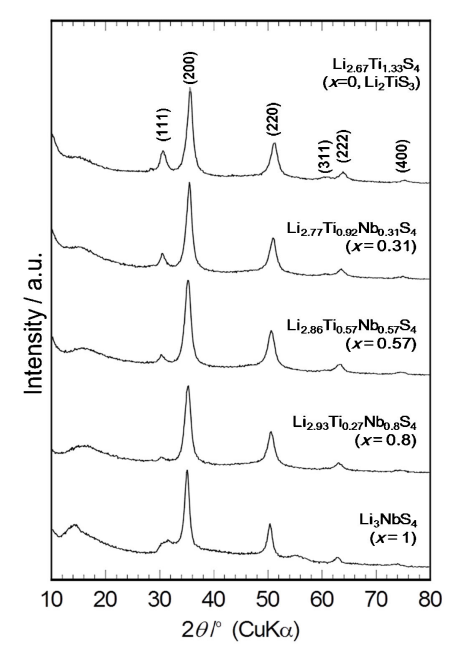

(c)

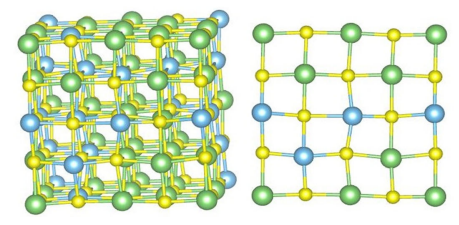

(b)

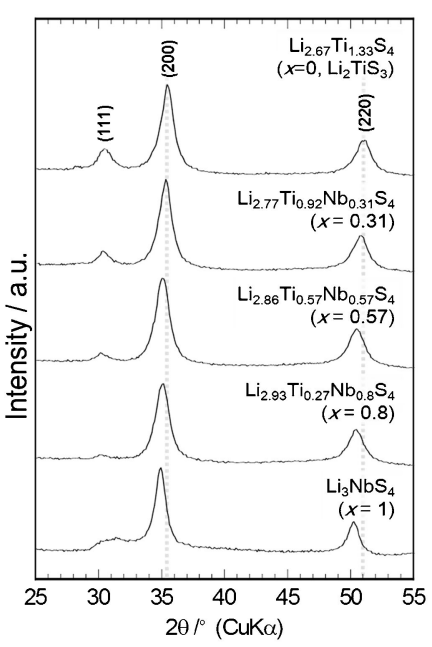

(d)

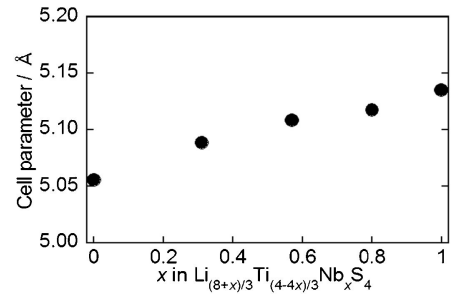

Fig. 1. (a) XRD patterns of $\mathrm{Li}_{(8+x) / 3} \mathrm{Ti}_{(4-4 x) / 3} \mathrm{Nb}_{x} \mathrm{~S}_{4}(x=0,0.31,0.57,0.80$, and 1$)$ prepared by mechanochemical synthesis, (b) magnified patterns of a, (c) structure model of cubic rock-salt obtained by structural relaxation using DFT-MD simulation, where green, blue, and yellow atoms correspond to $\mathrm{Li}, \mathrm{Ti} / \mathrm{Nb}$, and $\mathrm{S}$, respectively and (d) the change in lattice parameter of $\mathrm{Li}_{(8+x) / 3} \mathrm{Ti}_{(4-4 x) / 3} \mathrm{Nb}_{x} \mathrm{~S}_{4}$.

The rotation speed of ball milling was fixed at $510 \mathrm{rpm}$. Black powders were obtained for all of the samples.

The powder compressed pellets for the electronic conductivity measurements were prepared by pressing the obtained sample powders at $360 \mathrm{MPa}$ at room temperature.

Powder X-ray diffraction (P-XRD) measurements were performed at room temperature with a step size of $0.05^{\circ}$ using a D8 ADVANCE (Bruker AXS) diffractometer operating with $\mathrm{Cu} \mathrm{K} \alpha$ radiation. An air-sealing holder was used to avoid exposure to air. Lattice parameters were estimated by pattern fitting of XRD patterns with rock-salt structures using the TOPAS program (Bruker AXS).

The X-ray total scattering measurements for the X-ray pair distribution function (PDF) analysis were performed at SPring-8 BL28XU.9) The incident X-ray energy was $38.0 \mathrm{keV}$, and a $\mathrm{Si}$ (220) crystal $(2 \mathrm{~d}=3.840 \AA)$ monochromator was used. The analyzed Q-range was $0.7-14 \AA^{-1}$. The intensities of the incident $\mathrm{X}$-rays were monitored in an ionization chamber filled with $\mathrm{Ar}$ gas, while the scattered X-rays were detected with a CdTe detec- tor. A vacuum chamber was used to suppress air scattering. The collected data sets were corrected for the absorption, background, and polarization effects. Details of the correction and normalization procedures have been reported elsewhere. ${ }^{10)}$

The model structure has been constructed by density functional theory-based molecular dynamics (DFT-MD) simulations. The simulations were performed using OpenMX. ${ }^{11)}$ The exchangecorrelation functional used was GGA-PBE. The cut-off energy was 210 Ry. The basis functions (cut-off radius/orbital structure) used were 7.0 Bohr $/ \mathrm{s}^{2} \mathrm{p}^{2} \mathrm{~d}^{2}$ (Ti), 7.0 Bohr $/ \mathrm{s}^{2} \mathrm{p}^{2} \mathrm{~d}^{2} \mathrm{f}^{1}(\mathrm{Nb}), 7.0$ Bohr $/ \mathrm{s}^{2} \mathrm{p}^{2} \mathrm{~d}^{1}(\mathrm{~S})$, and $6.0 \mathrm{Bohr} / \mathrm{s}^{3} \mathrm{p}^{1}(\mathrm{Li})$. A norm-conserving pseudopotential was used. Eigenvector following algorism was used as the structure optimization. The atomic models were described using VESTA software. ${ }^{12)}$

The electrochemical cells used to test the samples were also constructed in an argon-filled glove box. The working electrodes were prepared using the active materials, acetylene black, and polytetrafluoroethylene (PTFE) with a weight ratio of 10:1:1. The loading of active materials was ca. $10 \mathrm{mg} \mathrm{cm}^{-2}$. An $1 \mathrm{M}$ solution 


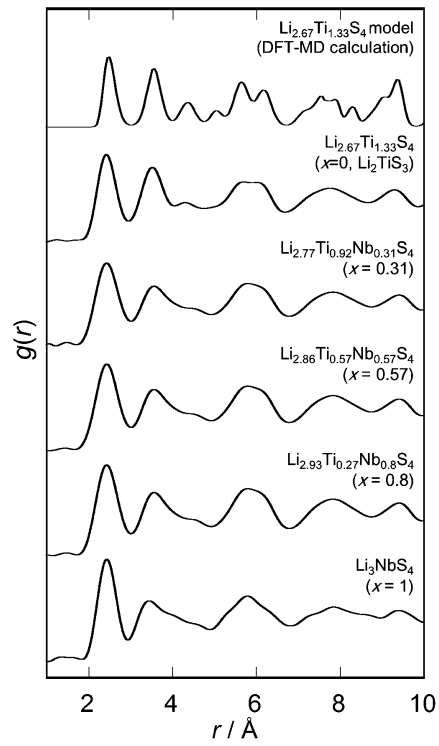

Fig. 2. Experimentally obtained X-ray PDF data $[g(r)]$. The PDF data of $\mathrm{Li}_{8 / 3} \mathrm{Ti}_{4 / 3} \mathrm{~S}_{4}$ obtained by DFT-MD simulation is shown for comparison.

of $\mathrm{LiPF}_{6}$ in a 50/50 (v/v) mixture of ethylene carbonate (EC) and dimethyl carbonate (DMC) (Tomiyama Pure Chemical Industries Ltd.) was used as the electrolyte. The counter electrode consisted of a $\mathrm{Li}$ foil disk ( $15 \mathrm{~mm}$ diameter, $0.2 \mathrm{~mm}$ thickness). The electrochemical measurements were performed at $30 \mathrm{C}$ using a charge-discharge unit (TOSCAT-3100, Toyo System) at a current density of $10 \mathrm{~mA} \mathrm{~g}^{-1}\left(0.1 \mathrm{~mA} \mathrm{~cm}^{-2}\right)$. The cut-off voltages for charging and discharging were 3.0 and $1.5 \mathrm{~V}$, respectively.

\section{Results and discussion}

Figures 1(a) and 1(b) shows the XRD patterns of the obtained samples. Each sample exhibited similar patterns and were identified as cubic rock-salt structure as seen in Fig. 1(c). In this structure, $\mathrm{Li}, \mathrm{Ti}$, and $\mathrm{Nb}$ atoms randomly share the cationic (4a) site as $[\mathrm{Li}, \mathrm{Ti}, \mathrm{Nb}]_{4 \mathrm{a}}[\mathrm{S}]_{4 \mathrm{~b}}$ in rock-salt structure formation $(F m \overline{3} \mathrm{~m})$. The positions of diffraction peaks shifted to low angles on increasing the niobium ratio. The calculated lattice parameter also increased with increasing niobium ratio as depicted in Fig. 1(d). This suggests that solid solutions between $\mathrm{Li}_{2} \mathrm{TiS}_{3}$ and $\mathrm{Li}_{3} \mathrm{NbS}_{4}$ were obtained. It is observed that three elements with different atomic sizes randomly share the same site. These materials should be obtained by the process used to prepare metastable materials, like the mechanochemical synthesis used in this study. Additional broad peak in the $2 \theta$ range of $10-20^{\circ}$ were observed. The peak would be attributable to non-Bragg diffraction which includes the information on short range order of usually less than $10 \AA$. The intensity increased with increasing $\mathrm{Nb}$ content, which would be because $\mathrm{Nb}$ show higher scattering factor than Ti.

Figure 2 shows the experimentally obtained X-ray PDF $[g(r)]$. The PDF data of $\mathrm{Li}_{8 / 3} \mathrm{Ti}_{4 / 3} \mathrm{~S}_{4}$ obtained by DFT-MD simulation is shown for comparison. The peak positions and the relative intensities of the experimental data of $\mathrm{Li}_{8 / 3} \mathrm{Ti}_{4 / 3} \mathrm{~S}_{4}$ agree well with those of the simulated one except for the sharpness of the profile, suggesting that the obtained samples have a cubic rock-salt analogue structure. The peaks around 2.5, 3.5, 4.3, 5.6, and $6.1 \AA$ are attributed to the distance of $\mathrm{M}-\mathrm{S}, \mathrm{S}-\mathrm{S}$ or $\mathrm{M}-\mathrm{M}, \mathrm{M}-\mathrm{S}, \mathrm{M}-\mathrm{S}$, and $\mathrm{M}-\mathrm{M}$ or $\mathrm{S}-\mathrm{S}(\mathrm{M}=\mathrm{Li}, \mathrm{Ti}, \mathrm{Nb})$ correlations, respectively. On the other hand, The pattern of $\mathrm{Li}_{3} \mathrm{NbS}_{4}$ is slightly different to that of rock salt structure. The PDF data of DFT-MD model of

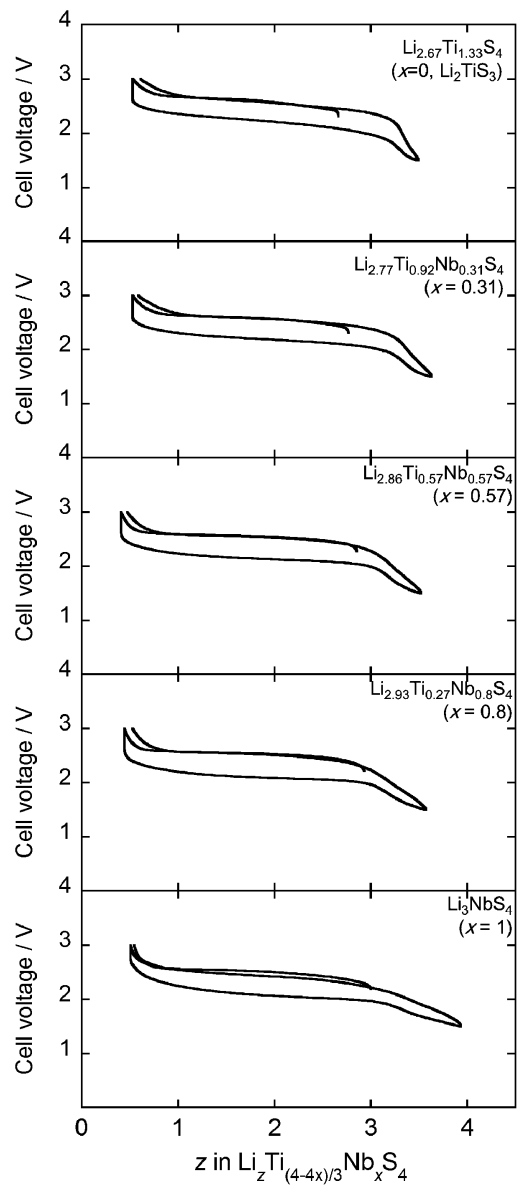

Fig. 3. Charge-discharge curves with the number of lithium atoms $(z)$ per formula unit $\mathrm{Li}_{z} \mathrm{Ti}_{(4-4 x) / 3} \mathrm{Nb}_{x} \mathrm{~S}_{4}$ as the $X$-axis.

$\mathrm{Li}_{3} \mathrm{NbS}_{4}$ (Fig. S1) indicated that the distances of some firstneighbor $\mathrm{Nb}-\mathrm{S}$ and second-neighbor $\mathrm{Nb}-\mathrm{Nb}$ pairs, which are respectively observed at the distance around 2.5 and $3.5 \AA$, are longer than those expected from average structure indexed into the rock salt structure. This leads to the decrease of the crystallinity of the sample. Thus, the middle range order in the compounds with $\mathrm{Nb}$ rich composition is relatively weak compared to those with Ti rich one.

Table 1 summarizes the electronic conductivity of the powder compressed pellets, and contains information regarding the density, calculated by lattice parameters obtained by XRD measurements $\left(d_{\mathrm{XRD}}\right)$; the powder true density, obtained using a gas pycnometer $\left(d_{\text {pow }}\right)$; the reversible capacity in charge-discharge performance, and the composition range of $z$ in the composition formula $\mathrm{Li}_{z} \mathrm{Ti}_{(4-4 x) / 3} \mathrm{Nb}_{x} \mathrm{~S}_{4}$ during charging and discharging. The conductivities of the samples $x=0,0.31,0.57$, and 0.80 were of the order of $10^{-5} \mathrm{~S} \mathrm{~cm}^{-1}$ in this study, and a dramatic increase in conductivity by the addition of small amounts of $\mathrm{Nb}$ was not observed. The $d_{\mathrm{XRD}}$ and $d_{\mathrm{POW}}$ showed similar values in all samples although $d_{\text {XRD }}$ tended towards slightly higher values. After considering that $d_{\text {POW }}$ includes the volume of closed pores inside of the particles, the obtained densities are reasonably sound. Figure 3 shows charge-discharge curves with the number of lithium atoms $(z)$ per formula unit $\mathrm{Li}_{z} \mathrm{Ti}_{(4-4 x) / 3} \mathrm{Nb}_{x} \mathrm{~S}_{4}$ as the $X$-axis. The density increased with increasing $\mathrm{Nb}$ ratio, and each sample charged and discharged with reversible capacities of $356-386 \mathrm{mAh} \mathrm{g}^{-1}$ in this study. The lithium composition $z$ in $\mathrm{Li}_{z} \mathrm{Ti}_{(4-4 x) / 3} \mathrm{Nb}_{x} \mathrm{~S}_{4}$ ranges between ca. 0.5 and over 3.5 , suggest- 
ing that more than 3 lithium ions are extracted and inserted in the structure of $\mathrm{Li}_{z} \mathrm{Ti}_{(4-4 x) / 3} \mathrm{Nb}_{x} \mathrm{~S}_{4}$ during charging and discharging. These results essentially agree with the previous reports on $\mathrm{Li}_{2} \mathrm{TiS}_{3}\left(\mathrm{Li}_{8 / 3} \mathrm{Ti}_{4 / 3} \mathrm{~S}_{4}\right)$ and $\mathrm{Li}_{3} \mathrm{NbS}_{4}{ }^{6), 8)}$ Although the gravimetric capacities slightly decrease with increasing $\mathrm{Nb}$ ratio, the volumetric capacities are almost similar in each sample because of the increase in density and the similar cell volume. For decreasing conducting additives and high performance, high electronic conductivity is favorable. Although a dramatic increase in conductivity was not obtained by the addition of small amounts of $\mathrm{Nb}$, it is relatively easy to increase the conductivity by preparing nanocomposites using conductive carbon and transition metal sulfides by mechanical milling. ${ }^{3), 13)}$ This is one of the many advantages of the mechanochemical process.

\section{Conclusion}

In this study, we successfully developed a $\mathrm{Li}_{2} \mathrm{TiS}_{3}-\mathrm{Li}_{3} \mathrm{NbS}_{4}$ solid solution by mechanochemical synthesis. In the solid solution, three elements of $\mathrm{Li}, \mathrm{Ti}$, and $\mathrm{Nb}$ randomly share the same cationic site. They act as electrode active materials over full composition ranges and show large reversible capacities of over $350 \mathrm{mAh}^{-1}$. It has been reported that $\mathrm{Ti}$ and $\mathrm{Nb}$ polysulfides show large capacities over wide ranges of Li composition and various crystalline phases including rock-salt, antifluorite, and amorphous phases. ${ }^{7)}$ These results clearly indicate that we are able to develop new sulfide-based electrode materials, and that more may be produced in future by choosing among the many options of compositions available.

Acknowledgement This work was supported by the "Research and Development Initiative for Scientific Innovation of New Generation Battery (RISING project)" of the New Energy and Industrial Technology Development Organization (NEDO; Japan). We thank Dr. T. Ohwaki, Dr. T. Okumura, Mr. K. Okamura, Ms. R. Azakami, and Mr. H. Yokota for their support with experiments and calculations during this study.

\section{Reference}

1) A. Hayashi, T. Matsuyama, A. Sakuda and M. Tatsumisago, Chem. Lett., 41, 886-889 (2012).

2) T. Matsuyama, A. Sakuda, A. Hayashi, Y. Togawa, S. Mori and M. Tatsumisago, J. Mater. Sci., 47, 6601-6606 (2012).

3) A. Sakuda, N. Taguchi, T. Takeuchi, H. Kobayashi, H. Sakaebe, K. Tatsumi and Z. Ogumi, Electrochem. Commun., 31, 71-75 (2013).

4) A. Sakuda, N. Taguchi, T. Takeuchi, H. Kobayashi, H. Sakaebe, K. Tatsumi and Z. Ogumi, ECS Electrochem. Lett, 3, A79-A81 (2014).

5) T. Matsuyama, A. Hayashi, T. Ozaki, S. Mori and M. Tatsumisago, J. Mater. Chem. A Mater. Energy Sustain., 3, 14142-14147 (2015).

6) A. Sakuda, T. Takeuchi, K. Okamura, H. Kobayashi, H. Sakaebe, K. Tatsumi and Z. Ogumi, Sci. Rep., 4, 4883 (2014).

7) A. Sakuda, T. Takeuchi, H. Kobayashi, H. Sakaebe, K. Tatsumi and Z. Ogumi, Electrochemistry, 82, 880-883 (2014).

8) A. Sakuda, T. Takeuchi, M. Shikano, H. Sakaebe and H. Kobayashi, Front. Energy Res., 4, 19 (2016).

9) H. Tanida, K. Fukuda, H. Murayama, Y. Orikasa, H. Arai, Y. Uchimoto, E. Matsubara, T. Uruga, K. Takeshita, S. Takahashi, M. Sano, H. Aoyagi, A. Watanabe, N. Nariyama, H. Ohashi, H. Yumoto, T. Koyama, Y. Senba, T. Takeuchi, Y. Furukawa, T. Ohata, T. Matsushita, Y. Ishizawa, T. Kudo, H. Kimura, H. Yamazaki, T. Tanaka, T. Bizen, T. Seike, S. Goto, H. Ohno, M. Takata, H. Kitamura, T. Ishikawa, T. Ohta and Z. Ogumi, J. Synchrotron Radiat., 21, 268-272 (2014) doi: 10.1107/S1600577513025733.

10) S. Kohara, M. Itou, K. Suzuya, Y. Inamura, Y. Sakurai, Y. Ohishi and M. Takata, J. Phys.: Condens. Matter, 19, 506101 (2007).

11) T. Ozaki, et al., OpenMX, 2016, http://www.openmx-square. org/.

12) K. Momma and F. Izumi, J. Appl. Cryst., 44, 1272-1276 (2011).

13) A. Sakuda, N. Taguchi, T. Takeuchi, H. Kobayashi, H. Sakaebe, K. Tatsumi and Z. Ogumi, Solid State Ionics, 262, 143-146 (2014). 